\title{
Bitumens Modified with Recycled Polymers
}

M. Murphy ${ }^{1}$, M.O'Mahony ${ }^{2}$, C. Lycett $^{1}$ and I. Jamieson ${ }^{3}$

(1) Irish Tar and Bitumen Ltd. Dublin, Ireland

(2) Department of Civil, Structural \& Environmental Engineering, Trinity College, Dublin 2, Ireland

(3) National Roads Authority, Dublin, Ireland.

\begin{abstract}
Increasing traffic loading and volumes on roads has led to the use of polymer modified binders to improve the performance of bitumen in terms of additional strength, durability and increased resistance to rutting and fatigue cracking. Generally those modifiers currently in use are virgin polymers but the research investigate the possibility of using waste polymers instead. The aim was to find a recycled polymer modified binder that would be similar to a proven modified binder (Polyflex 75) or would augment the properties of 100 penetration grade bitumen.

A wide range of recycled polymers was tested including polyethylenes, polypropylenes, polyetherpolyurethane, ground rubber and truck tyre rubber. Although there were some problems with stability in the bitumen some were found to be successful. The blen with $3 \%$ by mass of low density polyethylene substituted for $1 \%$ by mass of styrene butadience styrene had similar properties to that of Polyflex 75 although it had a lower stiffness. A combination of ethylene vinyl acetate with low density polyethylene showed similar viscosity to that of a 100 penetration bitumen while having an increased softening point. The blends showing promise need to be subjected to further investigation, in particular to evaluate how these blends perform in optimized bituminous mixes.
\end{abstract}

\section{Introduction}

Traditionally, conventional binders, such as 100 penetration grade (100 pen.) and 50 penetration grade (50 pen.), were used in road pavement construction. However, increased axle loading and braking power of vehicles in recent years required the durability and strength of the binder to resist rutting, fatigue and cracking tendencies of road pavements. One means of achieving this is to modify the bitumen with polymer. Polymer modified bitumens are known to increase the rutting resistance and decrease the temperature susceptibility of the binder as well as combat the effects of fatigue on the pavement [1].

Thousands of tonnes of waste plastic are produced every year [2]. Although the amount of waste being recycled or converted to energy is increasing it is still not enough to efficiently alleviate the problem. The aim of the research is to evaluate the performance of recycled (from 
waste polymer) modified bitumens and compare their properties with those of a standard bitumen and a polymer modified bitumen. In section 2 of the paper the recycled polymers used in the research are described followed in section 3 by a description of the tests used to evaluate them. In section 4 the results of the tests are presented followed in section 5 by a discussion of the results. The conclusions are presented in section 6.

\section{Materials}

\subsection{Bitumen}

The base binder used was a Middle East sourced 200 penetration bitumen. An already modified binder (commercial name, Polyflex 75) was the other base binder used in the research. Styrene butadiene styrene (SBS) is the modifier used in Polyflex but for the purposes of this research, some of it was removed and replaced with waste plastic rubber. A characterization of the base binders is given later in section 4.

\subsection{Description of polymers}

A wide variety of polymers were used to represent the range of waste plastics currently available. Brief descriptions of the polymers are given below.

\subsubsection{Polyethylene}

Polyethylene belongs to a group of polymers known as polyolefins; thermoplastic polymers. Several types of polyethylene exist but high, low and linear low density polyethylene are the most common. High density polyethylenes are used when stiffness, strength, heat tolerance and shrinkage are important. They are commonly used in food packaging e.g. milk bottles, carbonated drink bottles, industrial drums holding chemicals, cleaners, paint and antifreeze. Low density polyethylenes (LDPE) are used where impact strength, toughness and high elongation are important. Some applications of LDPE include bread packaging, sandwich bags, housewares, toys, buckets, wire and cable jacketing, carpet backing and foam for life preservers [3].

The polyethylenes used in this research were reprocessed high density polyethylene (HDPE) and reprocessed low density polyethylene. HDPE has good abrasion and moisture resistance and good barrier properties. The properties of the HDPE and LDPE used in this project are given in Table 1.

Some variability was apparent in the melting temperatures observed for the LDPE (the average is shown in Table 1) caused by the variation in density of the polymers used in the recycled LDPE. 


\begin{tabular}{|l|l|l|}
\hline Property & LDPE & HDPE \\
\hline Density $\left(\mathrm{g} / \mathrm{cm}^{3}\right)$ & 0.9535 & 0.9525 \\
\hline $\begin{array}{l}\text { Melting point } \\
\text { (average }{ }^{0} \mathrm{C} \text { ) }\end{array}$ & 115.1 & 129.1 \\
\hline
\end{tabular}

\subsubsection{Polypropylene}

Polypropylene is a 'harder' material than polyethylene. Two types were used: Homopolymer Polypropylene (HPP) and Copolymer Polypropylene (CPP). Polypropylene is used in garden furniture and surgical instruments as well as in luggage, appliances and automotive components [4]. Polypropylene has good heat and chemical resistance, resistance to deformation at elevated temperatures, high stiffness, surface hardness and toughness at ambient temperatures. However, it may exhibit brittleness at lower temperatures. The properties of CPP and HPP are given in Table 2.

\begin{tabular}{|l|l|l|}
\hline \multicolumn{3}{|c|}{ Table 2 - Properties of HPP and CPP } \\
\hline Property & HPP & CPP \\
\hline Density $\left(\mathrm{g} / \mathrm{cm}^{3}\right)$ & 0.9216 & 0.9102 \\
\hline $\begin{array}{l}\text { Average melting } \\
\text { point }\left({ }^{\circ} \mathrm{C}\right)\end{array}$ & 19.23 & 3.65 \\
\hline $\begin{array}{l}\text { Melt flow index } \\
\text { (g/600s) }\end{array}$ & 164.2 & 163.8 \\
\hline
\end{tabular}

\subsubsection{Polyetherpolyurethane (PEPU)}

The polyetherpolyurethance (PEPU) was supplied in the form of cut fibres. It is normally used in the weaving industry in the manufacture of clothing. Some other uses include extender and modifier for Acrylonitrile-butadiene-styrene ( $A B S$ ) thermoplastic, reinforcement fibres for mouldings and cement statues, replacement for natural and synthetic rubber in compounds and shoe soles as a partial replacement for rubber. It is quite strong and elastic. It has good resistance to chemicals and solvents. Its melting range is from 180 to $260^{\circ} \mathrm{C}$. The density of PEPU used in this project was $1.09 \mathrm{~g} / \mathrm{cm}^{3}$.

\subsubsection{Crumb rubber (TRRB)}

The rubber used was a sample of reclaimed truck tyres. Apart from use as a bitumen modifier, this rubber is also used for playground surfaces and athletic tracks, carpet backing, brake pads, roofing and cattlemats. The sample used was derived from ambient grind. This means that the tyre was torn apart at room temperature and then ground as opposed to being frozen before grinding. Table 3 contains information provided by the supplier and is an indication of content only. The density of the rubber is calculated to be $1.1-1.2 \mathrm{~g} / \mathrm{cm}^{3}$. 


\begin{tabular}{|l|l|}
\hline \multicolumn{2}{|c|}{ Table 3 - Contents of TRRB } \\
\hline Material & Content (\% by mass) \\
\hline Natural rubber & $25-50$ \\
\hline SBR/Butadiene content & $5-30$ \\
\hline Carbon black & $25-30$ \\
\hline $\begin{array}{l}\text { Processing agents (oil, zinc oxide, Sulphur, } \\
\text { etc.) }\end{array}$ & $20-25$ \\
\hline Benzene extraction & $3.5-9$ \\
\hline Acetone extraction & 10 (max.) \\
\hline Ash content & $4-6$ \\
\hline
\end{tabular}

\subsubsection{Rubber flour (GRRB)}

Rubber flour (GRRB) is another type of rubber examined. Content data for this polymer is not available. It was sourced from the elastic in diapers and swimwear and was supplied in powder form.

\subsubsection{Ethylene vinyl acetate}

Ethylene vinyl acetate (EVA is a thermoplastic polymer and has long been used in bitumen modification. It is generally added at a content of $5 \%$ by weight of bitumen [5] and this amount with 70penetration bitumen is quite popular [6]. The EVA blends used in this research are labelled as EVA1, EVA2 and EVA3 and their properties are given in Table 4.

\begin{tabular}{|l|l|l|l|}
\hline Table 4 - Properties of EVA & EVA2 & EVA3 \\
\hline Property & EVA1 & 20 & 33 \\
\hline $\begin{array}{l}\text { Vinyl acetate content (\% } \\
\text { by mass) }\end{array}$ & 14 & 20 & 45 \\
\hline $\begin{array}{l}\text { Melt flow index } \\
\text { (g/10min)@ } 190^{\circ} \mathrm{C} / 2.16 \mathrm{~kg}\end{array}$ & 2020 & 20 & \\
\hline
\end{tabular}

\subsubsection{Styrene Butadiene Styrene (SBS)}

Styrene butadiene styrene (SBS is a thermoplastic rubber or styrene block copolymer. SBS is a very strong and elastic polymer and derives these properties from the cross-linking of the elemental polymers into three-dimensional networks [6]. The polybutadiene component is the source of strength while the styrene is the source of the elasticity [5]. These polymers, being thermoplastic, will weaken or even dissociate at high temperatures and regain their original form on cooling.

\section{Methods}


The blends were tested using empirical tests of viscosity, softening point and penetration. The main aim of the research was to find blends that have properties similar or better than binders currently used in road construction. To facilitate comparison, tests were also conducted on conventional binders.

\subsection{Viscosity test}

The viscosity test is used to observe how a binder flows at different temperatures. It is an important property because it is essential to know how the bitumen behaves during mixing, compaction, laying and in service. The instrument used in this research was a cone and plate viscometer [6]. Three to four drops of bitumen were placed on the heated stationary plate. An upper plate rotates and shears the bitumen sample. The rate of shearing is then related to a scale from which the viscosity can be read. One of the problems encountered in this research was the determination of viscosity of blends containing fibres. The fibres, still intact in the bitumen, tended to spin out leaving a glut of bitumen at the edge of the spinning plate and a gap in the centre. Thus the accuracy of the result from shearing the sample was reduced.

\subsection{Softening Point}

The softening point of a bitumen is defined as 'the temperature at which a substance attains a particular degree of softness under specified conditions of test' by IP (Institute of Petroleum) $58 / 86$ [7]. A heated bitumen sample is placed in each of two brass rings. The rings are then placed in a bath of deionized water/glycerol is heated at a range of $5^{\circ} \mathrm{C}$ per minute until the binder deforms due to its decreasing viscosity with increasing temperature. Eventually, the ball bearing drops with the deforming bitumen and the temperature at which it hits a plate, 25 $\mathrm{mm}$ below the ring, is recorded [7].

An irregularity with this test was observed with the polymer modified binders. Some of the tests did not progress fully as is the case with conventional binders. In some instances the whole sample itself did not deform but softened at the interface of the bitumen sample and the ring due to the heat of the brass ring. It then fell under the weight of the bearing but did not deform i.e. the bitumen sample remained intact with the bearing resting on the top.

\subsection{Penetration test}

The penetration test is a test to determine the consistency of a bitumen binder [8]. Bitumen is placed in a standard cup and is maintained at $25^{\circ} \mathrm{C}$. A needle is then allowed to fall into the bitumen under a $100 \mathrm{~g}$ load for five seconds. The length the needle penetrates into the bitumen during this time is expressed in units of $0.1 \mathrm{~mm}$ and is known as the penetration (pen.) of the bitumen. Soft bitumens exhibit high penetrations and harder bitumens low penetration values.

\section{Property Test Results}


The objective of this part of the research was to find a blend of 200 penetration bitumen with recycled polymers, the properties of which would be similar to those of the Polyflex 75 and 100 penetration bitumen [9]. In the case of comparison with Polyflex 75, the desired binder would have a similar penetration and softening point with a lower viscosity. Any binder having properties better than that of 100 penetration bitumen would have a higher softening point with a similar penetration and viscosity. A similar viscosity is required because if the viscosity is much lower there is a risk of binder drainage in mixes while if it is too high mixing is difficult.

The typical penetration, softening point and viscosity values for the Polyflex 75 and the 100 penetration are given in Table 5 . The penetration values are in the same range but the viscosity and softening point of the Polyflex are much higher. Also included in Table 5 are the properties of the base 200 penetration bitumen used in the blends. The results of the standard tests on the polymer modified bitumens included blends with HDPE, LDPE, HPP, CPP, EVA, PEPU, TRRB and GRRB added in different proportions are presented below.

\begin{tabular}{|l|l|l|l|}
\hline \multicolumn{4}{|c|}{ Table 5 - Standard binder test results of Polyflex 75, 100 and 200 penetration bitumens } \\
\hline & Polyflex 75 & 100 pen. bitumen & 200 pen.bitumen \\
\hline Penetration $(0.1 \mathrm{~mm})$ & 100 & 108 & 185 \\
\hline Softening point $\left({ }^{\circ} \mathrm{C}\right)$ & 72 & 45.2 & 39.6 \\
\hline Viscosity (Pa.s) & & & \\
\hline$@ 135^{\circ} \mathrm{C}$ & 0.78 & 0.31 & 0.2 \\
\hline$@ 150^{\circ} \mathrm{C}$ & 0.49 & 0.17 & 0.12 \\
\hline$@ 180^{\circ} \mathrm{C}$ & 0.21 & 0.06 & 0.04 \\
\hline$@ 195^{\circ} \mathrm{C}$ & 0.14 & 0.04 & 0.03 \\
\hline
\end{tabular}

\subsection{Penetration results}

The penetration results of the 200 penetration bitumen with polyethylene, polypropylene and EVA blends are presented in Figure 1. The general trend for all blends is decreasing penetration (increasing stiffness) as the proportion of polymer is increased. However, in the case of the EVA3 the blend with $2 \%$ of EVA3 actually reduces stiffness but samples containing $4 \%$ and $6 \%$ of EVA3 showed increased stiffness. CPP hardens the bitumen considerably compared with other polymers where only $2 \%$ of CPP is required to give the same penetration as $3-4 \%$ of the other polymers. An addition of about $4 \%$ or above of any of the polyners except CPP tends to produce binders with penetrations of $100(0.1 \mathrm{~mm})$. Other blends using EVA and LDPE were also tested, the penetration results of which are presented in Table 6 . The blend showing most potential in Table 6 is the 4\% EVA1+2\%LDPE with a penetration value of $95(0.1 \mathrm{~mm})$. 


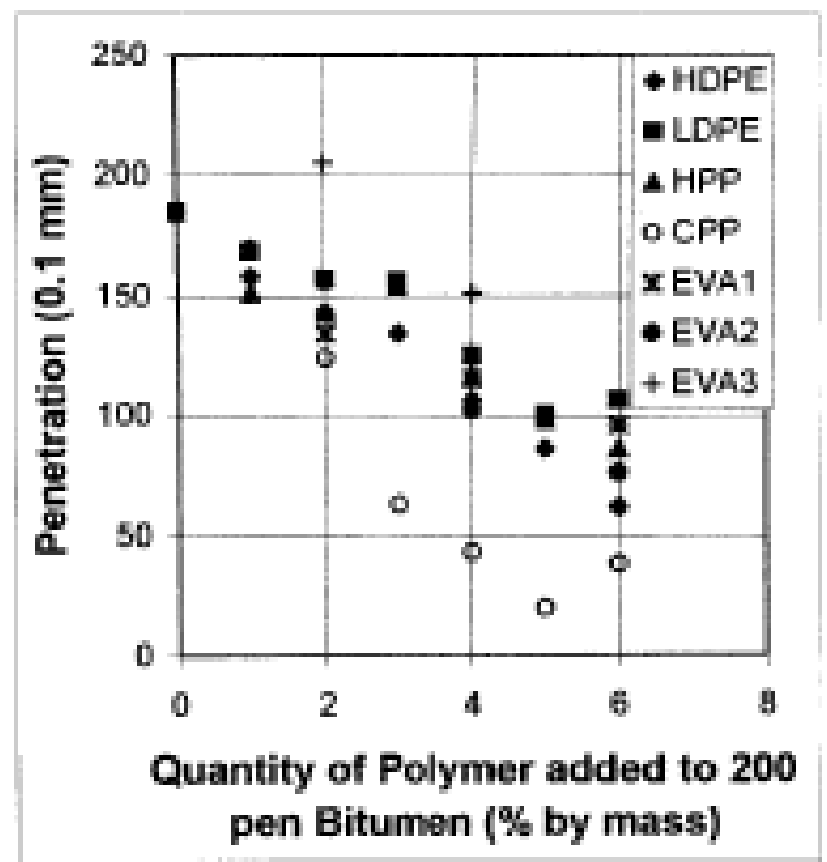

Figure 1. Penetration values of bitumen with polyethylene, polypropylene and EVA blends

\begin{tabular}{|l|l|}
\hline \multicolumn{2}{|l|}{ Table $\mathbf{6}$ - Penetrations of $\mathbf{2 0 0}$ penetration bitumen with EVA and LDPE blends } \\
\hline Blend type & Penetration $(0.1 \mathrm{~mm})$ \\
\hline $2 \%$ EVA1 + 4\% LDPE & 138 \\
\hline $4 \%$ EVA1 + 2\% LDPE & 95 \\
\hline $2 \%$ EVA2 $+4 \%$ LDPE & 85 \\
\hline $4 \%$ EVA2 + 2\% LDPE & 86 \\
\hline $2 \%$ EVA3 + 4\% LDPE & 154 \\
\hline $4 \%$ EVA3 $+2 \%$ LDPE & 159 \\
\hline
\end{tabular}

Penetration tests were also conducted on Polyflex 75 (P75) where quantities of SBS (modifier in P75) were removed and replaced with LDPE. Where $1 \%$ of SBS was removed and increasing quantities of LDPE were added, penetration increased to $125(0.1 \mathrm{~mm})$ for $1 \%$ addition of LDPE and fell to $102(0.1 \mathrm{~mm})$ in each of the cases of $+2 \%$ LDPE and $+3 \%$ LDPE.

Where $2 \%$ of SBS was removed and LDPE was added, penetration values of 123, 121 and 92 $(0.1 \mathrm{~mm})$ were observed for additions of $2 \%, 3 \%$ and $4 \%$ LDPE respectively. The final blend tested using P75 was a sample where $2 \%$ of LDPE was added but the amount of SBS was untouched. In this case, the penetration value was $89(0.1 \mathrm{~mm})$.

The results for the three blends made from 200 penetration bitumen with polyetherpolyurethane (PEPU) are $148(0.1 \mathrm{~mm})$ for $6 \%$ PEPU, $310(0.1 \mathrm{~mm})$ for $6 \%$ PEPU+GRRB+Oil and $142(0.1 \mathrm{~mm})$ for $10 \%$ PEPU. These penetration values are relatively high, particularly that for the $6 \%$ PEPU+GRRB+Oil. The addition of oil and ground rubber to this 
blend was to help improve the structure formed within the blend. The oil was used to help swell and dissolve the rubber and make it more compatible with the bitumen. Unfortunately, the only effect of the oil was to soften the binder substantially.

The last series of penetration tests was conducted on blends made with 200 penetration bitumen and truck tyre rubber (TRRB). An addition of 11\% TRRB gave a penetration result of $140(0.1 \mathrm{~mm})$ and for $16 \%$ TRRB the result was $145(0.1 \mathrm{~mm})$. These values are somewhat higher than the $100(0.1 \mathrm{~mm})$ required.

\subsection{Viscosity Results}

Viscosity tests were conducted at different temperatures on all blends and compared with the viscosity results of Polyflex 75 and 100 penetration bitumen presented in Table 5 . The aim is to find a blend which has lower viscosity values than P75 but similar to those of 100 penetration bitumen. The viscosity results for the 200 penetration bitumen with polyethylene and polypropylene blends are presented in Figure 2 where the decrease in viscosity with temperature is apparent in addition to an increase in viscosity with increasing levels of polymer. 


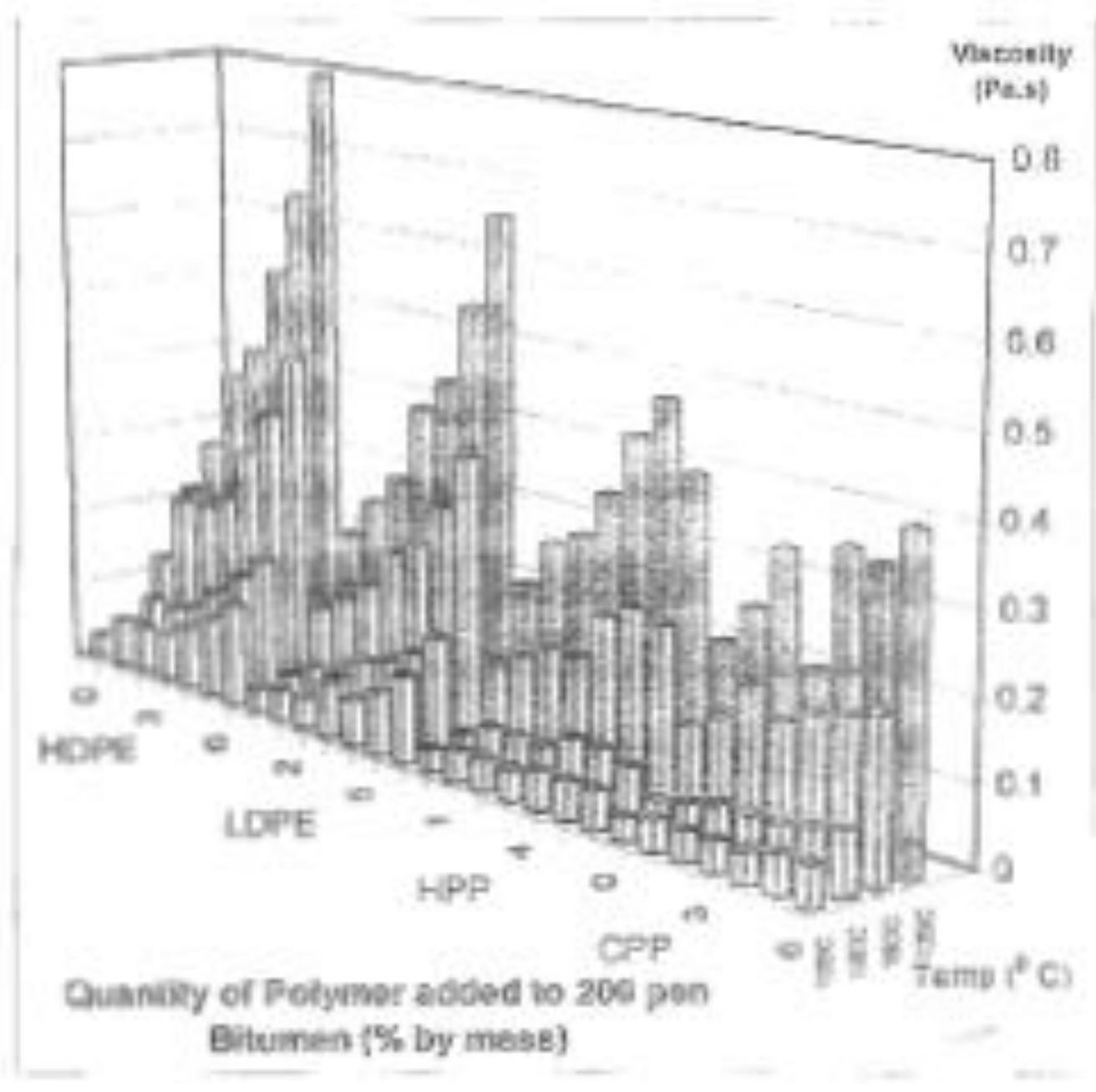

Figure 2. Viscosity results of bitumen with polyethylene and polypropylene blends

Blends with higher levels of HDPE at $135^{\circ} \mathrm{C}$ increase the viscosity of the base bitumen to 0.60.7Pa.s which is similar to that for P75 but much higher than for 100 penetration bitumen. Additions of $2 \%, 3 \%$ and $4 \%$ of HDPE increase viscosity to the $0.35-0.5$ Pa.s range. This is lower than the 0.49 Pa.s value of P75. Viscosity levels similar to that of 100 penetration bitumen at that temperature are achieved by $1 \%-2 \%$ additions of HDPE. At $180^{\circ} \mathrm{C}$ and $195^{\circ} \mathrm{C}$ the additions achieving similar viscosities to 100 penetration bitumen are the $2 \%-4 \%$ levels. $A$ similar review of the LDPE results indicates that the $3 \%-4 \%$ additions are likely to give viscosities similar to those of 100 penetration bitumen at all temperatures. In the case of HPP, the addition of $3 \%$ of HPP gives the closest set of viscosity results to those of 100 penetration bitumen at all temperatures. The amount of CPP required to be added to give similar results to that of 100 penetration bitumen is $2 \%$. 
The viscosities of the 200 penetration bitumen with EVA blends are presented in Figure 3 and the results of the 200 penetration bitumen with EVA and LDPE combinations are presented in Table 7.

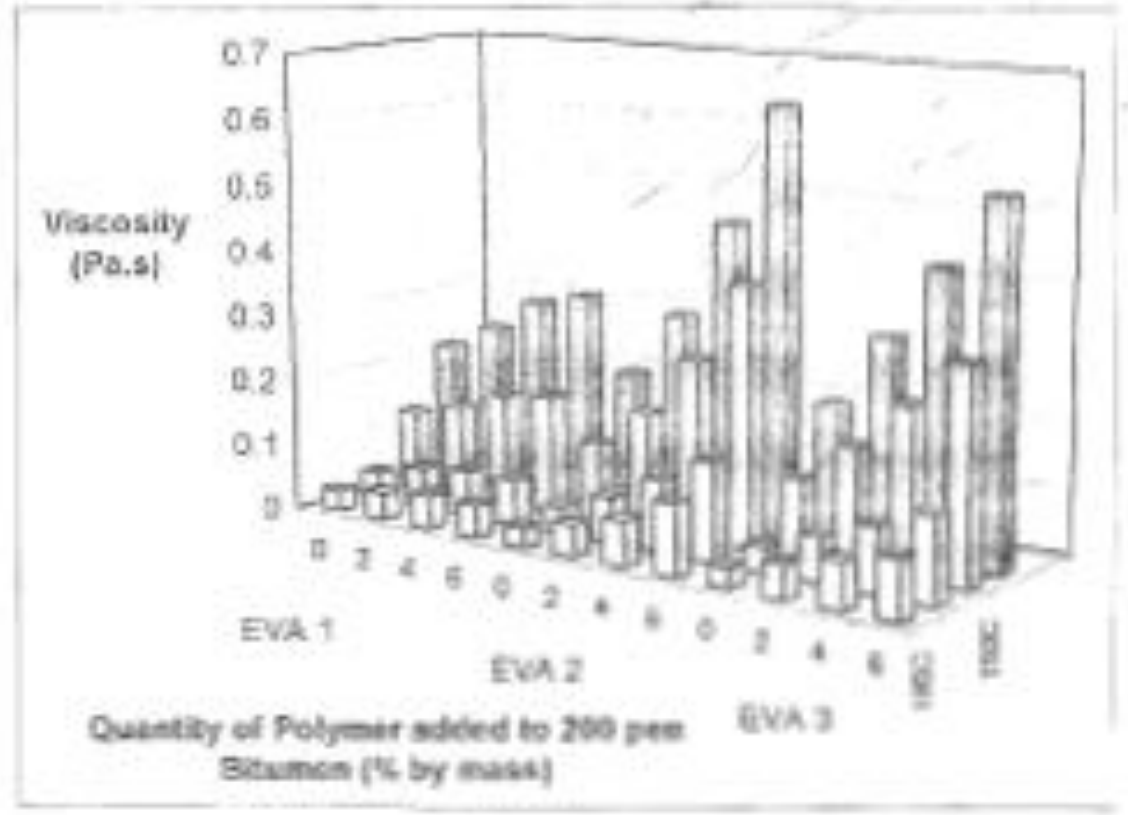

Figure 3. Viscosity results of bitumens with EVA blends

It can be seen in Figure 3 that the viscosities of the EVA1 combinations are lower than in the case of the EVA2, and EVA3 and that EVA2 exhibits the highest viscosities of all three. The higher additions of $4 \%$ and $6 \%$ increase the viscosity for the EVA2 and EVA3 more than in the case of the EVA1 where little change is evident with increasing amounts of EVA1. The $2 \%$ additions in the case of EVA2 an EVA3 have viscosities similar to those of 100 penetration bitumen. An addition of $4 \%$ of EVA1 is required to give similar viscosities.

The mixtures of EVA1 and LDPE (shown in Table 7) increase the viscosity results when compared with the EVA1 blends. The combinations of EVA2 and LDPE show similar viscosity results to the 6\% EVA2 results shown in Figure 3 whereas the EVA3 and LDPE blends are similar to the $6 \%$ EVA3 results.

The viscosity results for the Polyflex 75 (P75) blends are shown in Figure 4. Similar trends are apparent at all temperatures where the higher the level of LDPE in the sample the higher the viscosity. In the case where 1\% of SBS is removed from P75 and $1 \%$ is added and in the case where $2 \%$ of SBS is removed and $2 \%$ LDPE is added, the viscosities are lower than that of the original P75. 


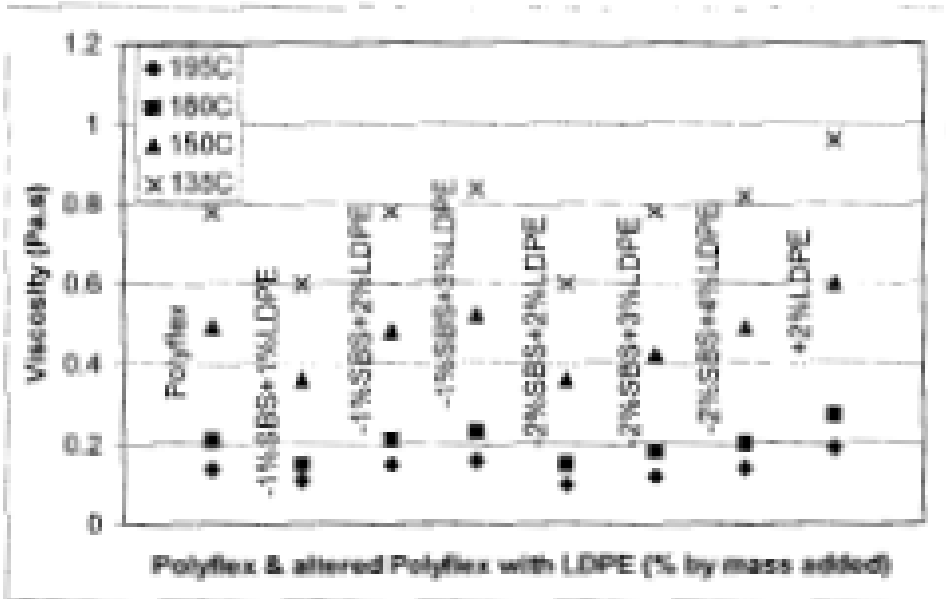

Figure 4. Viscosity results of Polyflex and LDPE blends

In Figure 5, the viscosities of the PEPU blends are presented. The viscosities are relatively low compared with other blends particularly that of the $M+6 \%$ PEPU $+3 \%$ GRRB + Oil blend. When comparing the $\mathrm{M}+6 \%$ PEPU and the $M+10 \%$ PEPU one can observe an increase in viscosity in the case of the $10 \%$ addition.

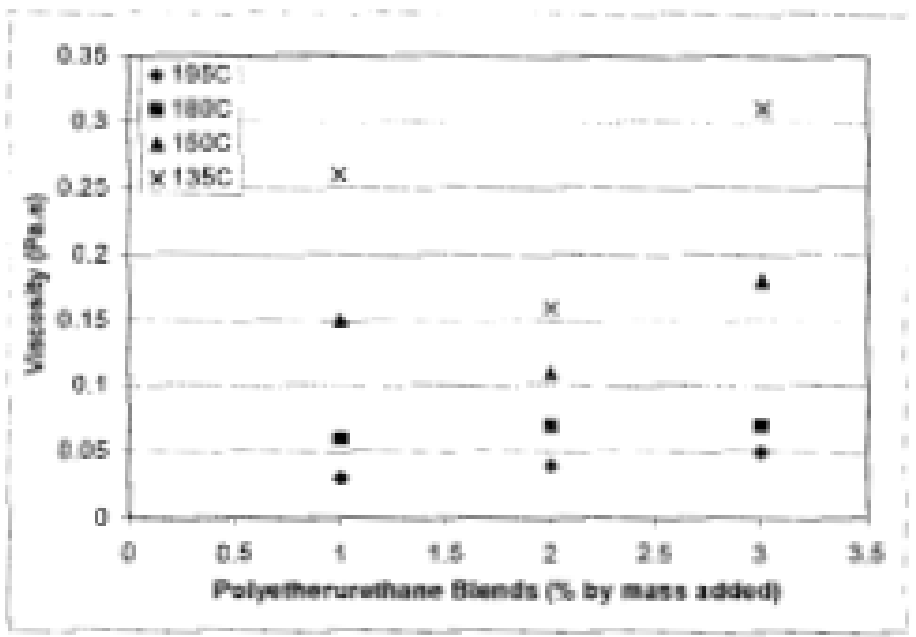

Figure 5. Viscosity results of bitumen with PEPU blends

A general increase in viscosity is evident as the level of TRRB is increased. At the higher temperatures the viscosities are similar to those of 100 penetration bitumen but at lower temperatures the viscosities of the TRRB blends are much higher, 0.5 Pa.s for $11 \%$ TRRB and 0.64 Pa.s for the $16 \%$ TRRB at $135^{\circ} \mathrm{C}$. 


\subsection{Softening Point Results}

The softening point results for polyethylene, polypropylenes and EVA blends are shown in Figure 6 . The general trend is increased softening point with increasing amounts of polymers in the binder. The highest increases in softening point were those for the CPP and this is particularly evident for the $4 \%+$ samples. Some of the blends show little change, particularly for HPP where the softening point is similar for all blends. The ideal blend will have a higher softening point than 100 penetration bitumen $\left(45.2^{\circ} \mathrm{C}\right)$ but one similar to that of PF75 $\left(72^{\circ} \mathrm{C}\right)$. The blends with a softening point around $70^{\circ} \mathrm{C}$ are $6 \%$ LDPE and $6 \%$ EVA1. $6 \%$ CPP gives a value of around $80^{\circ} \mathrm{C}$ whereas $6 \%$ EVA2, $6 \%$ HDPE and $4 \% \mathrm{CPP}$ give values of around $60^{\circ} \mathrm{C}$.

The softening points of the altered Polyflex and LDPE blends are shown in Table 8. Two values of softening point are given for some blends. This is because the two tests did not produce results within $1 \%$ of each other as required by the standard. Those blends having softening points around $70^{\circ} \mathrm{C}$ include almost all results except the P75 - 2\% SBS + 2\% LDPE blend with a value of $46.4^{\circ} \mathrm{C}$ and P75 $-2 \%$ SBS $+3 \%$ LDPE $\left(57^{\circ} \mathrm{C}\right)$ and P75 $-2 \%$ SBS $+4 \%$ LDPE $\left(58-59.4^{\circ} \mathrm{C}\right)$. The softening points of the PEPU blends are all quite low in the $33-45^{\circ} \mathrm{C}$ range as are those of $11 \%$ TRRB and $16 \%$ TRRB.

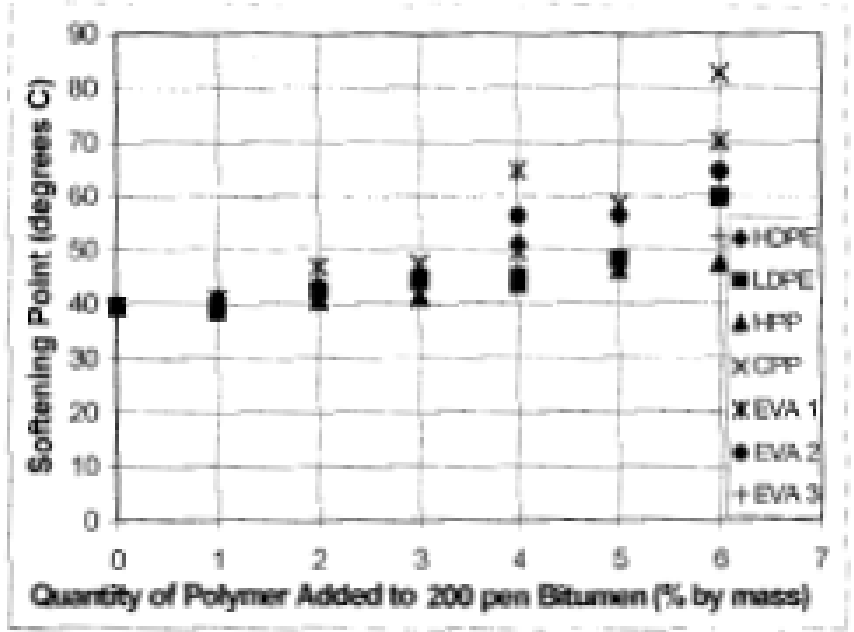

Figure 6. Softening point results for bitumen with polyethylene, polypropylene and EVA blends 


\section{Discussion}

The aim of the research was to identify recycled modified binders that give the most promising results in terms of being suitable as a replacement for bitumen. There are a number of blends, at first glance, which could be considered. Some have high softening points, like the bitumen and copolymer polypropylene blends. A high softening point is useful as it implies reduced temperature susceptibility of the material. A high viscosity is beneficial at low temperatures so that the blend will not flow or deform easily but a binder should flow easily at high temperatures so that it can coat the aggregates easily in the mixing process. The desirable penetration of the binder should be similar to that of a 100 penetration bitumen.

Although some polyethylene results appeared promising, the polyethylene tended to separate from the base bitumen. There were also some difficulties in the softening point test where the binder did not behave in the usual manner. In some cases the binder broke and separated from the ball bearing during the course of the test. The higher percentage blends showed similar viscosities to the Polyflex 75 but their softening points tended to be lower than $70+{ }^{\circ} \mathrm{C}$. Higher percentage blends tended to be unstable. A 4\% addition of LDPE to the bitumen gave the closest set of results to that of a 100 penetration bitumen. Even at that, the blend had a higher viscosity but the softening point was less at $44.2^{\circ} \mathrm{C}$ and the penetration higher at $125(0.1 \mathrm{~mm})$.

None of the polypropylenes are deemed suitable for further investigation because they were difficult to work with and separated too easily to make them feasible alternatives. The viscosities of these blends were also very low. Again, non-progressed softening point results were produced with these blends. They occurred at lower polymer content levels than the 200 penetration bitumen with polyethylene blends.

Of the bitumen with EVA none of the EVA3 blends were deemed appropriate for further work because of the minimal impacts they made in comparison with other blends. The lowest penetration value produced was $138(0.1 \mathrm{~mm})$ and the softening point was not raised above $52.2^{\circ} \mathrm{C}$. Some of the EVA blends and the EVA and LDPE appear suitable for further consideration. The $4 \% \mathrm{EVA} 2+2 \% \mathrm{LDPE}$ blend has a comparable penetration to 100 penetration and a raised softening point and viscosity.

Of the altered Polyflex blends, the P75 - 1\% SNS + 3\% LDPE blend was chosen because it has a comparable penetration to the $\mathrm{P} 75$ and has a higher softening point and viscosity. Of the other blends, the P75 - 1\% SBS + 2\% LDPE blend is the only one which could be considered in comparison to the P75. It has a comparable penetration and viscosity but, unfortunately, it does not retain the softening point of the base blend $\left(72^{\circ} \mathrm{C}\right)$.

The $6 \%$ and $10 \%$ PEPU blends have comparable softening points and viscosity values to the 100 penetration bitumen but their penetration values are too high. The $11 \%$ TTRB blend has a higher viscosity than a 100 penetration bitumen but is softer in terms of penetration and its softening point is only minimally increased. 


\section{Conclusions}

The aim of the project was to evaluate the 200 penetration bitumen blends containing waste polymer from recycled plastics and to identify the ones showing most promise in enhancing the properties of bitumen. A wide range of polymers was tested including polyethylene (low density and high density), polypropylene (including homopolymer and copolymer), ethylene vinyl acetate, styrene butadience styrene, polyetherepolyutethane, truck tyre rubber and ground rubber. The blends were subject to standard bitumen tests and their results were compared with those of a 100 penetration bitumen and a polymer modified binder, Polyflex 75 (containing styrene butadiene styrene). The conclusions drawn from the results are as follows:

1. Some of the waste polymers showed potential for enhancing the properties of bitumen but others did not.

2. Although some of the results for the polyethylenes appeared useful the tendency for them to separate from the bitumen suggests they should not be considered further.

3. The addition of polypropylene increased the softening point although viscosity values remain low. In this case, they showed some tendencies to separate from the bitumen.

4. The blends with low density polyethylene and ethylene vinyl acetate are worthy of further consideration because their properties are similar to that of 100 penetration bitumen and Polyflex 75.

5. Polyflex 75 with $1 \%$ styrene butadiene styrene removed and $3 \%$ low density polyethylene added compared well with standard Polyflex 75.

6. The $10 \%$ polyetherepolyurethane blend had comparable softening point and viscosity values to 100 penetration bitumen but its penetration value was higher. This blend is worthy of further consideration as it is a fiber mix and may be useful in the case of open graded mixes.

Those blends showing promise would need to be subjected to further more detailed investigation to evaluate in particular how they perform as part of a bituminous mix.

\section{Acknowledgement}

The authors would like to thank Irish Tar and Bitumen and the National Roads Authority of Ireland for supporting the project.

\section{References}

[1] Johnston, I. 'Modified bitumen for improved highway performance' J. Inst. High. and Trans. 41 (12) (1994) 18-19

[2] Plastics Industry Association (PIA). 'The Plastics Industry Yearbook 1997/98', (Technology Ireland, Ireland, 1997).

[3] Beam, R.J., 'Polyethylene, High Density (HDPE)'. Rubin, II (Ed.) Handbook of Plastic Materials and Technology. (John Wiley and Sons Inc., UK, 1990). 
[4] Hanna, R.D., 'Polupropylene'. Rubin II (Ed.) Handbook of Plastic Materials and Technology (John Wiley and Sons Inc., UK, 1990).

[5] Clifford, R.J., 'Porous asphalt - effect of binder type on elastic stiffness and ageing susceptibility'. MSc Thesis (Trinity College Dublin, Ireland 1996).

[6] Whiteoak, D and Shell Bitumen UK. 'The Shell Bitumen Handbook'., (Shell Bitumen, UK, 1990).

[7] Institute of Petroleum, 'Softening Point of Bitumen - Ring \& Ball'. Designation IP 58/86, UK, 1989.

[8] Institute of Petroleum, 'Standard Method of test for Penetration of Bituminous Materials'. Designation IP 49/86, UK, 1989.

[9] Murphy, M. 'Modification of Bitumen with Recycled Polymers'. MSc Thesis, (Trinity College Dublin, Ireland, 1999).

Publication Notes: The paper is published in Materials and Structures and should be cited as: Murphy, M., O'Mahony, M., Lycett, C. et al. Mat. Struct. (2000) 33: 438. doi:10.1007/BF02480663.

The link to the publication is here https://link.springer.com/article/10.1007/BF02480663

The article is copyrighted by RILEM and readers must contact RILEM for permission to reprint or use the material in any form. 